\title{
Reduction of non-steroidal anti-inflammatory drug induced gastric injury and leucocyte endothelial adhesion by octreotide
}

\author{
J M Scheiman, A Tillner, T Pohl, A Oldenburg, S Angermüller, E Görlach, G Engel, \\ K H Usadel, K Kusterer
}

\section{Division of \\ Gastroenterology, Department of Internal Medicine, \\ University of Michigan Medical School, Ann Arbor, \\ MI, USA \\ J M Scheiman \\ Department of Internal Medicine, JW Goethe-University, Frankfurt, Germany \\ A Tillner \\ T Pohl \\ A Oldenburg \\ K H Usadel \\ K Kusterer}

Department of Anatomy and Cell

Biology,

University of

Heidelberg

Germany

$S$ Angermüller

Sandoz Pharma

Basel, Switzerland

E Görlach

G Engel

Correspondence to:

Dr Klaus Kusterer,

Johann Wolfgang

Goethe-University,

Department of Internal

Medicine,

Theodor Stern Kai 7 ,

60590 Frankfurt am Main,

Germany.

Accepted for publication

28 January 1997
Abstract

Background-Non-steroidal anti-inflammatory drugs (NSAIDs) induce gastric ulcers.

Aims-To assess whether the somatostatin analogue octreotide prevents NSAID induced mucosal gastrointestinal damage in both animals and humans. The effect of octreotide on neutrophil adhesion to the endothelium was also evaluated. Methods-Male Sprague-Dawley rats were pretreated either with saline $(0.3 \mathrm{ml}$ subcutaneously) or octreotide (0.001-1 ng/ kg subcutaneously). After 30 minutes gastric ulcers were induced by the intragastric application of NSAIDs $(20 \mathrm{mg} / \mathrm{kg}$ indomethacin, $200 \mathrm{mg} / \mathrm{kg}$ aspirin, $200 \mathrm{mg} /$ $\mathrm{kg}$ ibuprofen, or $50 \mathrm{mg} / \mathrm{kg}$ diclofenac). Four hours later the rats were killed and gastric mucosal lesions were assessed by computed planimetry. To determine whether octreotide could prevent indomethacin induced injury in humans, 20 healthy volunteers were evaluated in a double blind, placebo controlled study. Results-Octreotide prevented NSAID induced gastric mucosal lesions $(p<0 \cdot 05)$. The dose response curve was $U$ shaped and the most effective dose was $0 \cdot 1 \mathrm{ng} / \mathrm{kg}$. Leucocyte adherence in submucosal venules of the stomach was evaluated by in vivo microscopy. Octreotide $(0.1 \mathrm{ng} / \mathrm{kg}$ subcutaneously) prevented indomethacin (20 $\mathrm{mg} / \mathrm{kg}$ intragastric) induced leucocyte adherence in gastric submucosal venules $(p<0 \cdot 05)$. Healthy human volunteers received $50 \mathrm{mg}$ indomethacin orally thrice a day concomitantly with either an identical placebo or $0.01 \mu \mathrm{g}, 0.1 \mu \mathrm{g}$, or $1 \mu \mathrm{g}$ octreotide subcutaneously thrice a day for three days. Injury was assessed by endoscopy. There was a negative correlation between the octreotide dose and injury score $(p<0.03$ for gastric injury, $p<0.001$ for duodenal injury).

Conclusions-Octreotide protects the stomach from NSAID induced gastric injury, probably via its ability to reduce NSAID induced neutrophilic adhesion to the microvasculature. Octreotide also ameliorated indomethacin induced gastric and duodenal injury in humans.

(Gut 1997; 40: 720-725)

Keywords: gastric ulcer, microcirculation, somatostatin analogue, non-steroidal anti-inflammatory drugs.
Aspirin and other non-steroidal anti-inflammatory drugs (NSAIDs) are the predominant cause of gastric and duodenal ulcers unrelated to Helicobacter pylori infection. Although clinically apparent NSAID ulcers occur in a very small fraction of those using the medications, given the vast numbers of patients exposed, NSAID toxicity to the upper gastrointestinal tract represents a substantial clinical problem and is the most frequent side effect of drugs in the United States. ${ }^{1}$ When studied by endoscopy, chronic NSAID users have been found to have gastric ulcers and erosions in $17 \%$ and $40 \%$ respectively, with duodenal ulcers and erosions seen in $4 \%$ and $13 \% .^{23}$ Gastroduodenal injury related to NSAIDs may have ominous potential as these agents have been implicated in the development of complicated peptic ulcer disease, presenting without antecedent symptoms, requiring surgery or causing death. ${ }^{4}$

The pathogenic mechanisms underlying NSAID related injury are complex, and reflect the ability of NSAIDs to have topical injurious effects which act in concert with systemic effects mediated by cyclooxygenase inhibition. Depletion of endogenous prostaglandins is thought to be central to the pathogenesis of NSAID related injury, based on the experimental evidence that antiprostaglandin antibodies induce ulcers in rabbits, ${ }^{5}$ and that oral administration of prostaglandins can reduce ulceration due to NSAIDs in humans. ${ }^{6}$ Recent attention has focused on the ability of NSAIDs to promote neutrophil-endothelial adhesion with subsequent ulceration. ${ }^{7}$ Interference with this interaction using antibodies to cell adhesion molecules or neutrophil depletion prevented experimental NSAID induced ulcers in vivo. ${ }^{89}$

Somatostatin has been found to have gastroprotective properties against ethanol or NSAID induced ulcers in rats. ${ }^{1011}$ The somatostatin analogue octreotide, at doses far below those necessary for the antisecretory actions of the drug, has also been shown to reduce ethanol induced mucosal lesions in rats. ${ }^{12}$ The gastroprotective effect was mediated via prevention of microcirculatory stasis and increased vascular permeability. In rats, enhanced somatostatin gene expression was found after ethanol induced injury. ${ }^{13}$ In support of the anti-inflammatory role of endogenous somatostatin, pretreatment with somatostatin monoclonal antibodies has been shown to exacerbate experimental colitis. ${ }^{13}$ 
Somatostatin receptors have been identified on leucocytes, ${ }^{14}$ and octreotide has recently been shown to suppress effectively the inflammatory reaction in rat studies in vivo. ${ }^{15}$ In the present paper, we studied the ability of octreotide to decrease NSAID induced injury in the stomach of rats. To examine the mechanism whereby octreotide may ameliorate NSAID ulcers, the effect of octreotide on indomethacin induced leucocyte-endothelial adherence was examined in postcapillary venules. The ability of octreotide to ameliorate endoscopically visible indomethacin induced gastric and duodenal injury was then examined in humans.

\section{Methods}

DRUGS

Octreotide acetate (SMS 201-995, Sandostatin $($ ) was obtained from Preclinical Research, Sandoz Pharma Ltd, Basel, Switzerland. Sandoz Inc, USA, supplied Sandostatin in vials of $50 \mu \mathrm{g} / \mathrm{ml}$ saline and identically appearing placebo prepared by a research pharmacist in a double blind fashion. The dilutions were such that the volume of injectate was $100 \mu \mathrm{l}$ per dose supplied in tuberculin syringes. All other drugs were purchased from commercial sources.

\section{NSAID INDUCED INJURY IN RATS}

Male Sprague-Dawley rats weighing 200-250 g were fasted for 24 hours with free access to water. Groups of rats ( $n>6 /$ group) were pretreated subcutaneously either with saline $(0.3 \mathrm{ml})$ or octreotide $(0.001-1 \mathrm{ng} / \mathrm{kg})$. After 30 minutes gastric mucosal lesions were induced by the intragastric application of 20 $\mathrm{mg} / \mathrm{kg}$ indomethacin. Four hours later the rats were killed by an overdose of ether and gastric mucosal lesions were assessed by computed planimetry. Under the conditions used, the stomachs of all animals were empty of food remnants. The stomach was cut open along the greater curvature and pinned flat on a cork plate covered with a white paper. Haemorrhagic lesions and erosions were similarly quantified using a microscope with a video camera connected to a black and white TV screen and an image analysing system (TEBA, Linden, Germany). The area of the glandular stomach and the area of the lesions were measured manually. Lesion quantity after indomethacin was expressed as percentage lesioned area relative to the area of the stomach. The person carrying out the analysis was not aware of the treatment the animal had received. After the establishment of the most effective dose of octreotide, we compared its effect on prevention of mucosal lesions induced by $20 \mathrm{mg} / \mathrm{kg}$ indomethacin, $200 \mathrm{mg} / \mathrm{kg}$ aspirin, $200 \mathrm{mg} / \mathrm{kg}$ ibuprofen, or $50 \mathrm{mg} / \mathrm{kg}$ diclofenac using the above protocol.

\section{MORPHOLOGICAL STUDIES}

Mucosal segments were fixed in $10 \%$ formaldehyde and embedded in Epon 802 (Fluka,
Buchs, Switzerland). Semithin sections $(0.5$ $\mu \mathrm{m})$ were cut for evaluation and for photomicrography after toluidine blue staining.

\section{IN VIVO MICROSCOPY PREPARATIONS}

The animals were placed on an operating table (Harvard, Boston, USA) and the rectal temperature was maintained at $37^{\circ} \mathrm{C}$ throughout the experiments. To avoid aspiration the rats had endotracheal tubes placed after tracheotomy. The abdomen was then opened by midline laparotomy. The vena cava was cannulated for the application of the fluorescent tracer.

The leucocyte adherence in the submucosal venules was studied with a modified in vivo microscopy technique similar to the one described by Guth and Rosenberg. ${ }^{16}$ The posterior wall of the stomach was fixed with fast adhesive glue to a heated metal plate $\left(37^{\circ} \mathrm{C}\right)$. The anterior wall of the stomach was fixed using a thin glass plate. The light of a mercury vapour lamp in the epi-illumination unit passed an excitation filter set (515-560 nm, dicroic mirror $580 \mathrm{~nm}$, barrier filter $580 \mathrm{~nm})$. The microcirculation was studied with a Nikon fluorescence objective $40 / 0 \cdot 55$ which resulted in final magnification on the video screen (Panasonic) of $\times 1500$. A CCD video camera (Pieper, Germany) was attached to the microscope. The experiments were recorded on video tape (video recorder: Panasonic S-VHS). On review of the videotapes each image was digitalised with an image analysing system (Datacube, Peabody, MA, USA). Each of the $512 \times 512$ pixels had 8 bit resulting in a resolution of 256 gray values. The software (TEBA) allows the measurements of the areas of the vein cross sections. Fifteen minutes after the end of the operation an intravenous bolus $(1 \mathrm{ml} / \mathrm{kg})$ of a $1 \%$ solution of rhodamine $6 \mathrm{G}$ ( $\mathrm{mw} 479$ ) for in vivo staining of leucocytes was applied. Adherent leucocytes were visualised in 10 different submucosal venules. A leucocyte was considered adherent if it did not move for 30 seconds. Leucocyte adherence was expressed as the area of adherent leucocytes in a percentage of the vein cross section. The areas were measured by computed planimetry. The animal studies were approved by the review board of the government of Hessen, Germany.

\section{ACUTE INDOMETHACIN GASTROTOXICITY IN} HUMANS

Twenty healthy volunteers (11 men, nine women) with no history of gastrointestinal disease, alcohol misuse, or regular NSAID use were recruited for this study by advertisement. Informed consent was obtained by the investigators. An endoscopy to ensure mucosal integrity was performed on all subjects before drug administration. The subjects were randomly assigned to octreotide $(0.01,0.1$, or $1 \mu \mathrm{g}$ ) or identical placebo, given subcutaneously three times a day. The octreotide was to be taken for three days in combination with $50 \mathrm{mg}$ oral indomethacin three times a 
TABLE I Rating scale of observed injury

\begin{tabular}{ll}
\hline Endoscopic appearance & Score \\
\hline Normal (erythema included) & 0 \\
$\leq 5$ erosions & 1 \\
$6-15$ erosions & 2 \\
>15 erosions or spontaneous bleeding & 3 \\
Ulcer ( $\geq 4$ mm depth) & 4 \\
\hline
\end{tabular}

day with food. On the morning of the fourth day the subjects underwent repeat endoscopy to measure the visible areas of injury. The same endoscopist (JS) performed all procedures. Neither the subjects nor the endoscopist was aware of drug assignment. Table I gives the rating scale used to grade the endoscopic findings. The study was approved by the

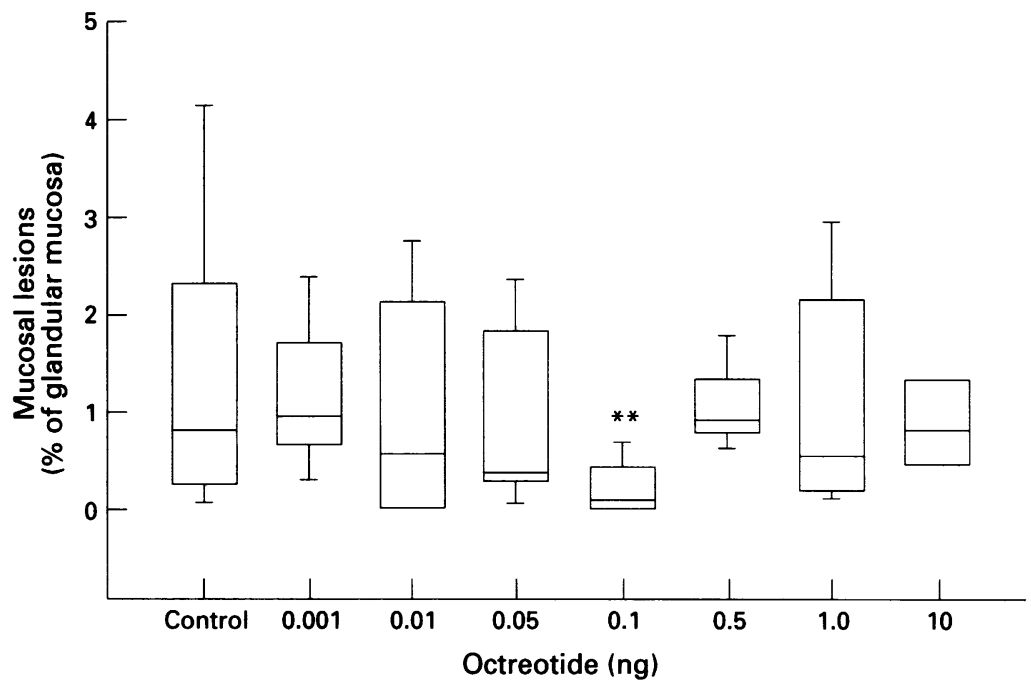

Figure 1: Effect of octreotide on the area of gastric lesions four hours after the intragastric application of $20 \mathrm{mg} / \mathrm{kg}$ indomethacin in rats. Octreotide was given subcutaneously 30 minutes before the application of indomethacin. The lesioned area is expressed as a percentage of the total area of glandular stomach. Box plots show median values and the 10th, 25th, 75th, and 90th percentiles; $n=10 /$ group; ${ }^{* *} p<0.01$ octreotide v NaCl group (ANOVA on ranks with Dunn's method for within group comparison).

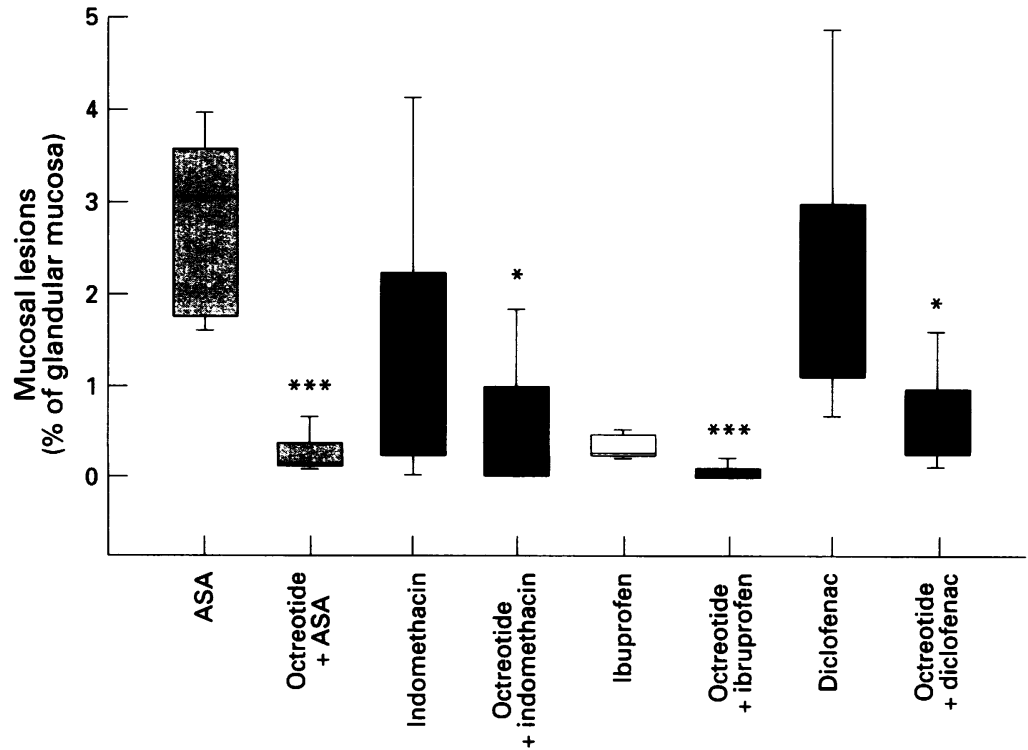

Figure 2: Effect of octreotide on the area of gastric lesions four hours after the intragastric application of $20 \mathrm{mg} / \mathrm{kg}$ indomethacin, $200 \mathrm{mg} / \mathrm{kg}$ aspirin, $200 \mathrm{mg} / \mathrm{kg}$ ibuprofen, or $50 \mathrm{mg} /$ $\mathrm{kg}$ diclofenac in the rat. Octreotide $(0 \cdot 1 \mathrm{ng} / \mathrm{kg})$ was given subcutaneously 30 minutes before the application of NSAIDs. The lesioned area is expressed as a percentage of the total area of glandular stomach. Box plots show median values and the 10th, 25th, 75th, and 90th percentiles; $n=12 /$ group. ${ }^{*}<<0.01,{ }^{*} \star_{p}<0.001$ octreotide $+N S A I D \mathrm{v}$ corresponding NSAID group (ANOVA on ranks with Dunn's method for within group comparison).
Institutional Review Board for Human Investigation on 11 November 1993.

\section{STATISTICAL ANALYSIS}

Data are presented as box plots showing median values and the 10 th, 25 th, 75 th, and 90th percentiles. Significant differences between the drug treated groups and their respective controls were assessed by KruskalWallis one way analysis of variance (ANOVA) on ranks using Dunn's method for within group comparision. To test for a relation between octreotide dosing and observed human gastric injury we used the knowledge that the drug does not worsen injury. To exploit all the information inherent in the data, a one sided linear by linear association test was performed. In both cases exact $p$ values were calculated using StatXact (Cytel Corp).

\section{Results}

MACROSCOPIC INJURY IN RATS

The stomach of rats treated with intragastric indomethacin $(20 \mathrm{mg} / \mathrm{kg})$ developed mucosal lesions. The lesioned area amounted to $0 \cdot 82 \%$ (25\% range $0.26 \% ; 75 \%$ range $2.33 \%$ ) of the glandular stomach. Octreotide was tested for protective effects against indomethacin induced gastric lesions after subcutaneous doses of 0.001 to $1 \mathrm{ng} / \mathrm{kg}$. Figure 1 shows that octreotide caused a dose dependent reduction of the lesioned area at doses of 0.001 to $0.1 \mathrm{ng} /$ $\mathrm{kg}$ with a maximal effect at a dose of $0 \cdot 1 \mathrm{ng} / \mathrm{kg}$. This dose reduced the area of mucosal lesions to $0.08 \%$ (25\% range $0.00 \% ; 75 \%$ range $0.42 \%$ ) of the whole glandular surface of the stomach $(\mathrm{p}<0.01)$. This corresponded to a $90 \%$ (25\% range $49 \% ; 75 \%$ range $100 \%)$ inhibition of the mucosal lesions. The higher doses of octreotide, 0.5 and $1 \mathrm{ng} / \mathrm{kg}$, did not reduce the lesioned area, corresponding to the earlier experiments with ethanol induced gastric lesions. ${ }^{12}$

The maximal effective dose $(0 \cdot 1 \mathrm{ng} / \mathrm{kg})$ of octreotide prevented mucosal lesions not only induced by indomethacin, but also by aspirin, ibuprofen, and diclofenac (Fig 2).

\section{MORPHOLOGICAL STUDIES}

In areas with macroscopically intact gastric mucosa the histological analysis of rats pretreated with octreotide disclosed occasionally intact gastric mucosa (Fig 3a), but the predominant observation was NSAID induced gastric mucosal injury with superficial damage of luminal epithelial cells. Gastric pit and gland cells were intact. The areas of macroscopic mucosal lesions were found to have complete surface damage and the damage extended to the mid-mucosa consisting of necrosis of the glandular cells (Fig 3b). Octreotide reduced the area of macroscopically visible mucosal lesions. Deeper mucosal injury was never found in rats treated with octreotide in sections which appeared macroscopically intact. However, the few mucosal lesions after pretreatment 

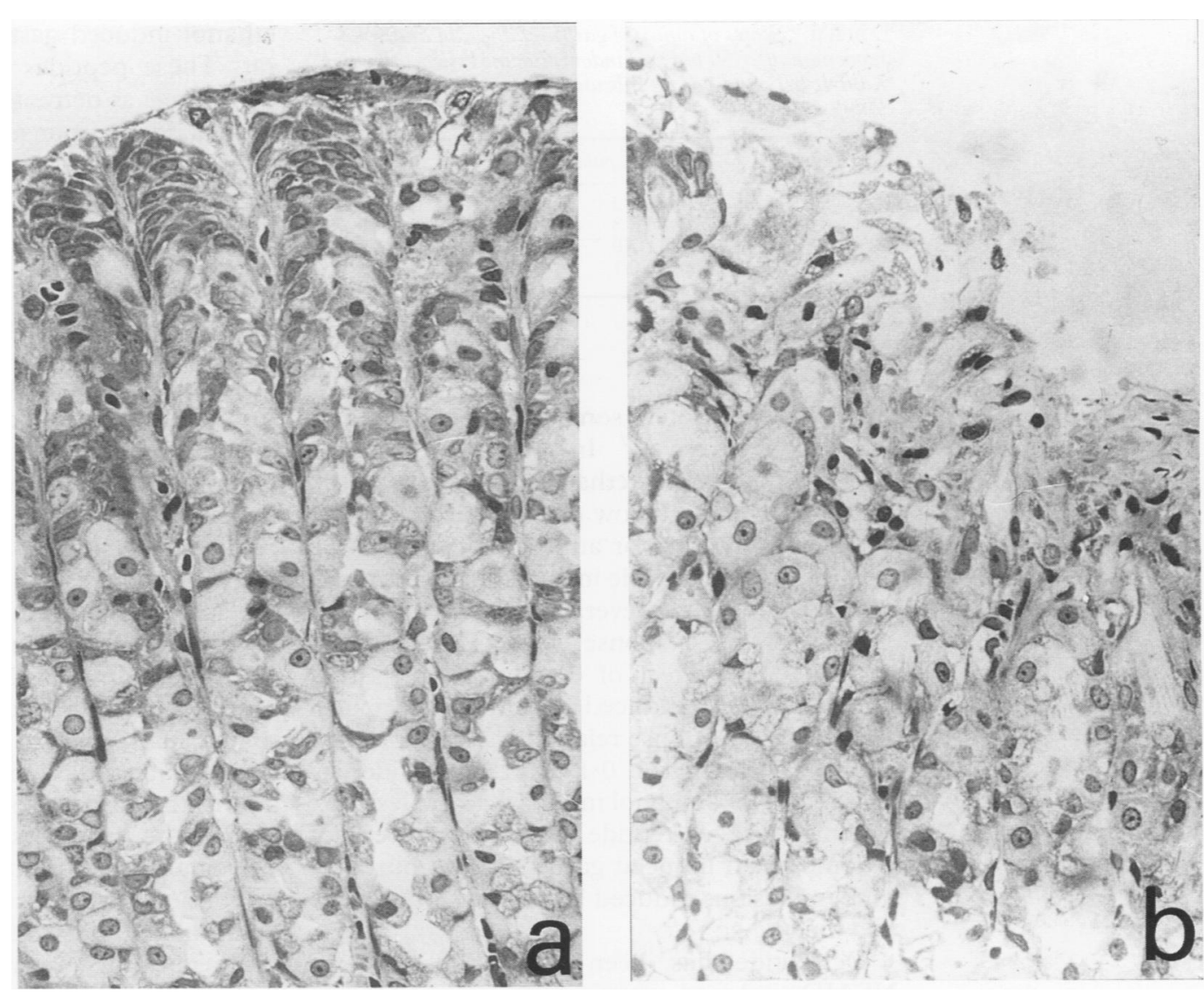

Figure 3: Gastric mucosa four hours after the intragastric application of $20 \mathrm{mg} / \mathrm{kg}$ indomethacin. (a) Octreotide (0.1 ng/ kg) or saline (b) was given subcutaneously 30 minutes before the application of indomethacin. In areas with macroscopically intact gastric mucosa the histological analysis showed occasionally intact gastric mucosa (a). The areas of macroscopic mucosal lesions were found to have complete surface damage and the damage extended to the mid-mucosa consisting of necrosis of the glandular cells (b) (toluidine blue, original magnification $\times 4$ ).

with octreotide had the same histological appearance as groups pretreated with vehicle.

\section{LEUCOCYTE ADHERENCE IN RAT SUBMUCOSAL VENULES}

Leucocyte adherence was measured in the submucosal venules of the stomach (Fig 4). Four hours after the application of intragastric indomethacin $(20 \mathrm{mg} / \mathrm{kg})$ there was a significant increase $(p<0.001)$ in adherent leucocytes. Pretreatment with the maximal effective dose of subcutaneous octreotide $(0 \cdot 1 \mathrm{ng} / \mathrm{kg})$ prevented indomethacin induced leucocyte adherence in gastric submucosal venules $(p<0.001)$.

\section{HUMAN STUDIES}

Table II and Figure 5 summarise the effects of octreotide on indomethacin induced injury in humans. No side effects other than mild burning at the injection site were seen. Although the study suffered from a relatively low degree of injury in the placebo group, confirmation for an existing trend in both scorings came from the test for linear association, in which the actual values of the scores and the dosages are entered into the model. This test showed that for both gastric $(p<0.03)$ and duodenal $(p<0.001)$ injury there was a negative correlation between the dose levels and the measured scores - for example, higher octreotide dosages led to smaller grades of injury. Thus in humans, as in rats, very low doses of octreotide were associated with a reduction in NSAID induced upper gastrointestinal injury.

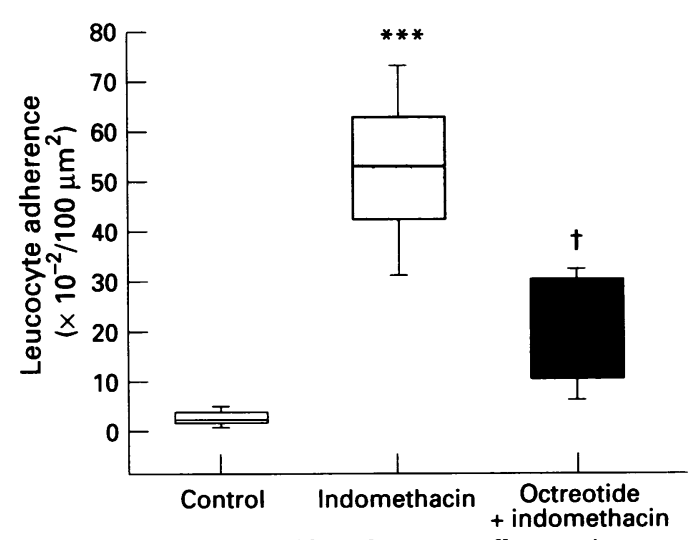

Figure 4: Effect of octreotide on leucocyte adherence in postcapillary venules of the rat stomach induced by indomethacin four hours after the intragastric application of $20 \mathrm{mg} / \mathrm{kg}$ indomethacin. Octreotide $(0 \cdot 1 \mathrm{ng} / \mathrm{kg})$ was given subcutaneously 30 minutes before the application of indomethacin. Adherent leucocytes were seen in 10 different submucosal venules. A leucocyte was considered adherent if it did not move for 30 seconds. Leucocyte adherence was expressed as the area of adherent leucocytes in a percentage of the vein cross section. Box plots show median values and the 10th, 25th, 75th, and 90th percentiles. ${ }^{\star \star *} p<0.001$ indomethacin $\mathrm{v} \mathrm{NaCl} \mathrm{group;}+p<0.001$ octreotide+ indomethacin $\mathrm{v}$ indomethacin group (ANOVA on ranks with Dunn's method for within group comparision); $n=12 /$ group. 
TABLE II Scores of injury of gastric epithelium and duodenum after $50 \mathrm{mg}$ oral indomethacine thrice daily and $0,0 \cdot 01,0 \cdot 1$, and $1 \cdot 0 \mu \mathrm{g}$ subcutaneous octreotide thrice daily

\begin{tabular}{|c|c|c|}
\hline Dose $(\mu g)$ & Gastric epithelium & Duodenum \\
\hline $\begin{array}{l}0 \\
0 \cdot 01 \\
0 \cdot 1 \\
1 \cdot 0\end{array}$ & $\begin{array}{lllll}0 & 0 & 1 & 3 & 2 \\
2 & 4 & 0 & 0 & 3 \\
0 & 1 & 1 & 2 & 0 \\
0 & 0 & 0 & 0 & 1\end{array}$ & $\begin{array}{lllll}0 & 0 & 3 & 2 & 3 \\
4 & 0 & 0 & 1 & 1 \\
1 & 0 & 2 & 1 & 0 \\
0 & 0 & 0 & 0 & 0\end{array}$ \\
\hline
\end{tabular}

\section{Discussion}

Octreotide is a potent somatostatin analogue in vitro and in vivo. ${ }^{17}$ In a previous study octreotide prevented ethanol induced mucosal lesions at extremely low doses, well below the amounts necessary for antisecretory actions. ${ }^{12}$ The effect of octreotide in ameliorating ethanol induced injury, however, followed a biphasic $\mathrm{U}$ shaped dose-response curve. Here, we investigated the effect of octreotide on gastric mucosal lesions induced by indomethacin. A similar dose-response relation was found, with the maximal effect at $0.1 \mathrm{ng} / \mathrm{kg}$ octreotide, as in the model of ethanol induced gastric lesions. At this dose octreotide not only prevented indomethacin induced gastric lesions but also mucosal lesions induced by aspirin, ibuprofen, and diclofenac.

Octreotide has been shown to prevent NSAID induced gastric mucosal injury in rats, ${ }^{11}$ but in this study the dose used was five orders of magnitude higher $(10 \mu \mathrm{g} / \mathrm{rat})$ than in our investigations. The hypothesised mechanisms for the observed action of high doses of octreotide - for example, inhibition of acid secretion, and decreased leukotriene generation and substance $P$ and vasoactive intestinal polypeptide concentrations ${ }^{11}-$ do not apply to the low doses we used. A biphasic U shaped dose relation in the ethanol gastric lesion model was first noted by Diel and Szabo ${ }^{18}$ for linear somatostatin. Laszlo and coworkers ${ }^{10} 19$ tested several somatostatin analogues in the

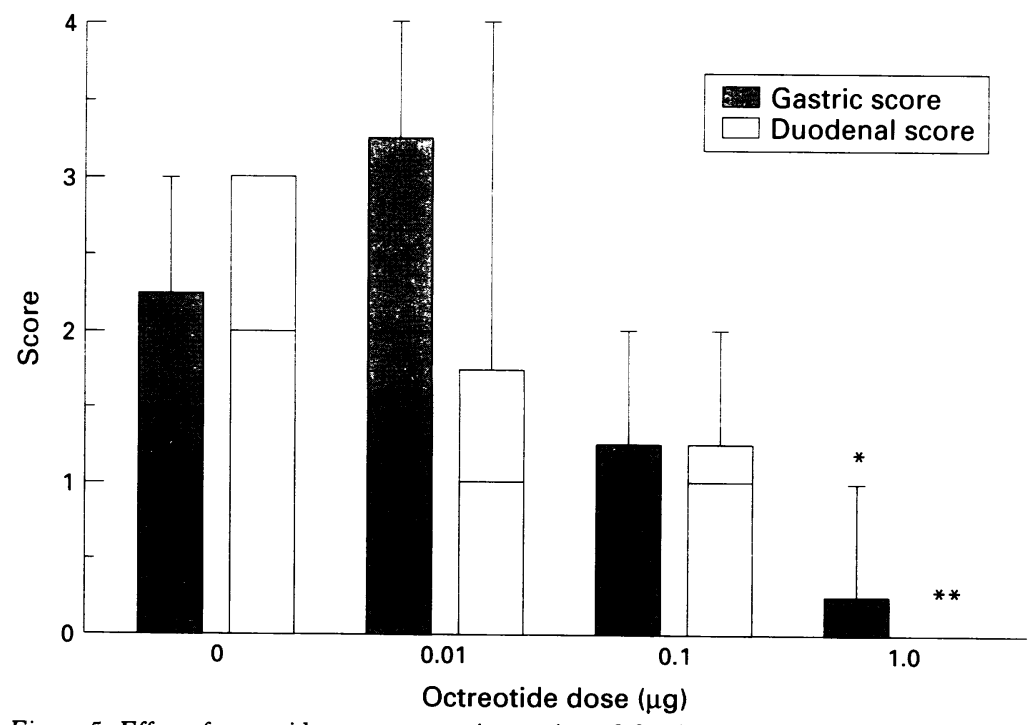

Figure 5: Effect of octreatide on macroscopic gastric and duodenal injury score in humans induced by indomethacin. Box plots show median values and the 10th, $25 \mathrm{th}, 75 \mathrm{th}$, and 90 th percentiles. Confirmation of an existing trend in both scores was by one sided linear by linear association, in which the actual values of the scores and the dosages enter into the model. This test shows that for both gastric $\left({ }^{*} p<0.03\right)$ and duodenal $\left({ }^{*} p<0.001\right)$ injury there is a negative correlation between the dosage concentrations and the measured scores. ethanol induced gastric erosion model in the rat. These peptides were active in a similar dose range as octreotide and also followed a $U$ shaped dose-response relation. They suggested two explanations: the somatostatin receptors might be inactivated by higher doses (desensitisation) or the involvement of two types of somatostatin receptors with high and low affinity binding sites respectively..$^{10} 19$ Another likely explanation for the reduction in the pharmacological effect of octreotide despite increasing the dose is receptor autoinhibition. An analogous effect of somatostatin on myenteric cholinergic transmission has been found. ${ }^{20}$ The excitatory effect of somatostatin under unstimulated conditions activates a cholinergic pathway via action on GABA $_{A}$ receptors whereas $\mathrm{GABA}_{B}$ receptors mediate the inhibitory action of somatostatin in the cholecystokinin stimulated state. ${ }^{20}$

An alternative explanation for our findings postulates differences in the affinity for somatostatin among the effector cells in the complex network which modulates inflammation in the gastrointestinal tract. Somatostatin receptors are expressed in high density in intestinal vessels in humans. ${ }^{21}$ Thus the doseresponse relation in this study may reflect a multiplicity of dose related actions on somatostatin receptors on mononuclear cells, endothelial cells, and enteric neurons.

Previous studies with microscopic analysis of ethanol induced damage to rat gastric mucosa after treatment with a prostaglandin disclosed a reduction in deep mucosal injury, but surface damage of the mucosa was not prevented. ${ }^{22}$ In our studies, macroscopically visible areas of haemorrhage induced by NSAIDs were less than those in the ethanol treated rats. Octreotide reduced both the areas of visible mucosal lesions and deeper mucosal injury. The areas without mucosal lesions showed superficial damage which was not influenced by the octreotide treatment, analogous to prostaglandin mediated cytoprotection. Sections through the few mucosal lesions in the octreotide group did not differ from the mucosal lesions in rats not pretreated with octreotide.

Octreotide prevents ethanol induced stasis and reduction of mucosal blood flow. ${ }^{12}$ These findings suggest that the protective effect of octreotide may be linked to improvements in microcirculation. It has recently been proposed that neutrophil-endothelial cell adhesion is an early event in the pathogenesis of NSAID induced gastric ulceration. Aspirin and indomethacin have been shown to promote leucocyte adherence in mesenteric venules. ${ }^{23}$ Animals with depleted neutrophils show reduced gastric ulceration after NSAID treatment, ${ }^{8}$ and a monoclonal antibody against the CD18 leucocyte adhesion molecule prevented indomethacin induced gastric damage. ${ }^{9}$ In an in vitro system with human neutrophils added to confluent human umbilical vein endothelial cells, incubation with aspirin promoted neutrophil adherence to endothelium via $\mathrm{CD} 11 \mathrm{a} / \mathrm{CD} 18$ and $C D 11 \mathrm{~b} / \mathrm{CD} 18$ dependent interactions with intercellular adhesion molecule-1. ${ }^{24}$ 
In the present study we measured the in vivo leucocyte adherence induced by indomethacin in the postcapillary venules of the stomach. Indomethacin significantly increased leucocyte adherence to postcapillary venules of the mucosa. Octreotide also significantly reduced indomethacin induced leucocyte adherence. The protective effect of octreotide is therefore likely to be associated with its capacity to prevent indomethacin induced leucocyte adherence. Although not specifically considered in this study, the ability of octreotide to reduce NSAID induced neutrophil-endothelial interaction may reflect activation of the somatostatin receptors known to be present on mononuclear cells and vascular endothelium. ${ }^{14}$ The modulation by octreotide of the expression of mononuclear and endothelial cell adhesion molecules and cytokines are potential pathophysiological mechanisms which may explain our findings, but require further investigation.

The results of the double blind, placebo controlled study in humans confirm the ability of octreotide to prevent NSAID induced injury, extending the findings made in the rat model. Although not specifically studied in humans, the mechanism by which octreotide ameliorated the indomethacin induced injury is not likely to be related to antisecretory effects of the drug, as the doses utilised were one hundredth of the antisecretory doses utilised clinically. Based on the rat data, the ability of octreotide to reduce NSAID induced injury via effects on neutrophil adhesion represents a novel approach to the management of NSAID induced ulcer disease worthy of further study. A major limitation of octreotide for the current clinical management of NSAID induced ulcer is the requirement for parenteral administration. Given the low doses of octreotide used, the cost of medication is unlikely to represent a barrier to the clinical application of these findings. The development of oral octreotide analogues ${ }^{19}$ will be of considerable interest for study as potential preventive agents of NSAID induced ulcers.

In summary, the present study considered the protective effect of octreotide in NSAID induced gastric ulceration. In rats, octreotide protects against indomethacin, aspirin, ibuprofen, and diclofenac induced gastric lesions, most likely via its ability to reduce NSAID induced neutrophil adhesion to the microvasculature. The potential for octreotide to reduce NSAID induced injury in humans was also confirmed.

These studies were supported in part by grant KU-622/1-2 from the Deutsche Forschungsgemeinschaft and by Sandoz Pharma Ltd (Basel). We express our gratitute to $\mathrm{Dr} F$ Länger, Department of Pathology, for the help with the morphology. W also thank Gabriele Sties for excellent technical assistance.
1 Fries JF. NSAID gastropathy: the second most deadly rheumatic disease? Epidemiology and risk appraisal. $\mathcal{F}$ Rheumatol 1991; 18: 6-10.

2 Silvoso GR, Ivey KJ, Butt JH, Lockard OO, Holt SD, Sisk $\mathrm{C}$, et al. Incidence of gastric lesions in patients with rheumatic disease on chronic aspirin therapy. Ann Intern Med 1979; 91: 517-20.

3 Lockard OO, Ivey KJ, Butt JH, Silvoso GR, Sisk C, Holt $\mathrm{S}$. The prevalence of duodenal lesions in patients with rheumatic disease on chronic aspirin therapy. Gastrointest Endosc 1980; 26: 5-7.

4 Armstrong CP, Blower AL. Non-steroidal anti-inflammatory drugs and life threatening complications of peptic ulceration. Gut 1987; 28: 527-32.

5 Redfern JS, Feldman M. Role of endogenous prostaglandins in preventing gastrointestinal ulceration: induction of ulcers by antibodies to prostaglandins. Gastroenterology 1989; 96: 596-605.

6 Graham DY, Agrawal NM, Roth SH. Prevention of NSAID-induced gastric ulcer with misoprostol: multicentre, double-blind, placebo-controlled trial. Lancer 1988; ii: $1277-80$.

7 Lee M, Aldred K, Lee E, Feldman M. Aspirin-induced acute gastric mucosal injury is a neutrophil-dependent process in rats. Am f Physiol 1992; 263: G920-6.

8 Wallace JL, Keenan CM, Granger DN. Gastric ulceration induced by non-steroidal anti-inflammatory drugs is neutrophil-dependent process. Am F Physiol 1990; 259: G462-7.

9 Wallace JL, Arfors K-E, McKnight GW. A monoclonal antibody against the CD18 leukocyte adhesion molecule prevents indomethacin-induced gastric damage in the prevents indomethacin-induced gastric dam

10 Laszlo F, Pavo I, Penke B, Balint GA. The effects of somatostatin and some of its tetrapeptide fragments on ethanol-induced gastric mucosal erosion in rat. Life Sci 1987; 41: 1123-6.

11 Karmeli F, Eliakim R, Okon E, Rachmilewitz D Somatostatin effectively prevents ethanol- and NSAIDinduced gastric mucosal damage in rats. Dig Dis $S c i$ 1994 39: $617-25$.

12 Kusterer K, Buchheit KH, Schade A, Bruns C, Neuberger $\mathrm{C}$, Engel $\mathrm{G}$, et al. The somatostatin analogue octreotide protects against ethanol-induced microcirculatory stasis and elevated vascular permeability in rat circulatory stasis and elevated vascular permeability in

13 Babyatsky MW, Brand SJ, Karmeli F, Podolsky DK, Walsh $\mathrm{JK}$, Wong H, et al. Enhanced somatostatin expression JK, Wong $\mathrm{H}$, et al. Enhanced somatostatin expression modulates gastric injury and experime

14 Bhathena SJ, Louie J, Schechter GP, Redman L, Wahl L, Recant L. Identification of human mononuclear leukocytes bearing receptors for somatostatin and glucagon. Diabetes 1981; 30: 127-31

15 Karalis K, Mastorakos G, Chrousos GP, Tolis G. Somatostatin analogues suppress the inflammatory reaction in vivo. $\mathcal{f}$ Clin Invest 1994; 93: 2000-6.

16 Guth PH, Rosenberg A. In vivo microscopy of the gastric microcirculation. Am $\mathcal{f}$ Dig Dis 1972; 17: 391-8.

17 Bauer W, Briner U, Doepfner W, Haller R, Huguenin R, Marbach P, et al. SMS 201-995: a very potent and Marbach P, et al. SMS 201-995: a very potent and selective octapeptide analogue of somat

18 Diel F, Szabo S. Dose-dependent effects of linear and cyclic somatostatin on ethanol-induced gastric erosions: the role of mast cells and increased vascular permeability in the rat. Regul Pept 1986; 13: 235-43.

19 Laszlo F, Pavo I, Penke B, Balint GA. Protective effect of an orally administered, highly potent somatostatin analog (RC-121) against absolute ethanol-induced hemorrhagic erosions of the rat gastric mucosa. Life Sci 1989; 44: 1573-8.

20 Roberts DJ, Hasler WL, Owyang C. GABA mediation of the dual effects of somatostatin on guinea pig ileal myenteric dual effects of somatostatin on guinea pig ileal myenteric G953-60.

21 Reubi JC, Mazzucchelli L, Laissue JA. Intestinal vessels express a high density of somatostatin receptors in human inflammatory bowel disease. Gastroenterology 1994; 106: 951-9.

22 Lacy ER, Ito S. Microscopic analysis of ethanol damage to rat gastric mucosa after treatment with a prostaglandin. Gastroenterology 1982; 83: 619-25.

23 Asako H, Kubes P, Wallace J, Wolf RE, Granger DN. Modulation of leukocyte adhesion in rat mesenteric venules by aspirin and salicylate. Gastroenterology 1992; 103: $146-52$.

24 Yoshida N, Takemura T, Granger DN, Anderson DC, Wolf RE, McIntire LV, et al. Molecular determinants of aspirin-induced neutrophil adherence to endothelial cells. Gastroenterology 1993; 105: 715-24. 